\title{
Stevens-Johnson syndrome
}

INSERM

\section{Source}

INSERM. (1999). Orphanet: an online rare disease and orphan drug data base. StevensJohnson syndrome. ORPHA:36426

Stevens-Johnson syndrome is a limited form of toxic epidermal necrolysis (see this term) characterized by destruction and detachment of the skin epithelium and mucous membranes involving less than $10 \%$ of the body surface area. 